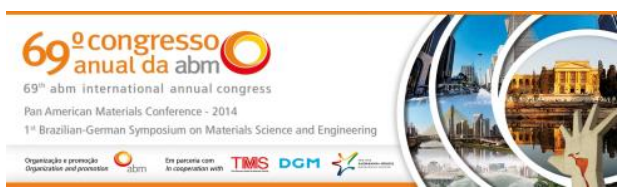

Tema: Gestão de Meio Ambiente e recuperação e tratamento de rejeitos

\title{
RECICLAGEM DE TERRAS RARAS A PARTIR DE RESÍDUOS DE BATERIAS DE NÍQUEL METAL HIDRETO: ETAPA DE CARACTERIZAÇÃO*
}

\section{Resumo}

Catharina Rebucci Ribeiro Orsoli Fernando Nascimento Codelo 2 Viviane Tavares Moraes ${ }^{3}$

Denise Corcce Romano Espinosa 4

Com o crescimento do mercado tecnológico, os modelos de aparelhos eletrônicos sofreram adaptações, principalmente em relação aos tamanhos os quais se tornaram: menores, mais leves e com mais rapidez operacional. Alguns resíduos de equipamentos eletroeletrônicos contem terras raras (TRs) em sua composição. Os elementos que compõem as terras raras de REEEs são compostas por 17 elementos (grupo lantanídios, escândio e ítrio) que conseguem suprir estas novas necessidades do mercado. Este trabalho tem como finalidade a reciclagem destas TRs entendendo primeiramente a individualidade de cada tipo de bateria, já que suas destinações pós-uso não possuem rotas definidas de tratamento. Para a caracterização foram coletadas cerca de $4,5 \mathrm{~kg}$ de pilhas e baterias obtidas de uma entidade recicladora da USP. Os materiais foram divididos em 12 grupos com semelhanças especificas como: marca e local de produção. Em seguida as pilhas e baterias passaram pelo britador de mandíbulas, e após 3 dias de secagem à temperatura ambiente, os materiais passaram por um moinho de facas utilizando grelhas de $3 \mathrm{~mm}$. O material moído e dividido em frações de $100 \mathrm{~g}$, sendo uma fração para digestão ácida, uma para perda ao fogo e o restante direcionado para a rota hidrometalúrgica para extração, identificação e quantificação das TRs presentes em pilhas e baterias de Níquel Metal Hidreto, visando à obtenção seletiva das TRs.

Palavras-chave: Reciclagem; Níquel metal hidreto; Terras raras; Caracterização.

\section{RARE EARTH'S RECYCLING FROM NICKEL METAL HYDRIDE BATTERIES: CHARACTERIZATION STAGE}

\begin{abstract}
With the development of the technology market, the electronic gadgets were suffered a lot of adaptations, especially in the matter of sizes questions which have become: smaller, lighter and more operational speed. Some electronic equipment residues have Rare earths (Res) in those compositions. The elements that compose the WEEEs Rare earths are composed by 17 elements (lanthanides group, scandium and yttrium) that can support these new electronically equipment needs. This work aims to recycle these TRs, first understanding that the individuality of each battery type, because of their post-use destinations have no defined some specific place. For characterization, about $4.5 \mathrm{~kg}$ of batteries were collected, received from a recycling entity from USP. The materials were divided into 12 groups with a similar specification as brand and producing location. After then the batteries went through the jaw crusher, and after 3 days of drying at room temperature, the material went through a Wiley mill using $3 \mathrm{~mm}$ grids. The milled material and divided into $100 \mathrm{~g}$ fractions, with a part to acid digestion, one to one for loss on ignition and the rest were directed to the hydrometallurgical route (to the extraction, identification and quantification of TRs present in Nickel metal hydride batteries), looking for a selectively obtain of the TRs.

Keywords: Recycling; Nickel metal hydridre; Rare earths; Characterization.

1 Graduando em Tecnologia Ambiental, Senai Mario Amato, São Bernardo do Campo, SP, Brasil.

2 Professor do Senai Mario Amato, São Bernardo do Campo, SP, Brasil.

3 Pós Doutoranda em Engenharia Metalúrgica e de Materiais, Escola Politécnica, USP, São Paulo, SP, Brasil.

4 Professora do Dept. Eng. Metalúrgica e de Materiais, Escola Politécnica, USP, SP, Brasil.
\end{abstract}

\footnotetext{
* Contribuição técnica ao 69ำ Congresso Anual da ABM - Internacional e ao 14ํㅡㄹ ENEMET - Encontro Nacional de Estudantes de Engenharia Metalúrgica, de Materiais e de Minas, 21 a 25 de julho de 2014, São Paulo, SP, Brasil.
} 


\section{INTRODUÇÃO}

As baterias de $\mathrm{NiMH}$ foram desenvolvidas devido a alta contaminação da destinação inadequada das baterias de $\mathrm{NiCd}$ que foi sendo limitado o uso do recurso de metais tóxicos, pois em $1989,54 \%$ de $\mathrm{Cd}$ e $88 \%$ de $\mathrm{Hg}$ foram encontrados em residuais de pilhas e baterias [1]. Em 1991 foi aprovada a legislação da Comunidade Europeia (91/157/EEC- Batteries and Accumulators Directive), que visou limitar a concentração do mercúrio, cadmio e do chumbo, padronizando a identificação das pilhas que poderiam ser recicladas [2,3]. Já no Brasil em junho de 1999 foi regulamentada a Resolução CONAMA 257/99 fala sobre a destinação dessas pilhas e baterias e a limitação dos metais tóxicos de acordo com cada tipo de bateria [4].

Os resíduos de equipamentos eletroeletrônicos são: circuitos eletroeletrônicos, telefones celulares, tablets, dentre outros uma aplicação muito encontrada as terras raras é em pilhas e baterias de níquel metal hidreto. Atualmente uma alternativa para a obtenção de terras raras é através de resíduos de equipamentos eletroeletrônicos (REEE) [5].

As pilhas e baterias de NiMH entraram no mercado em 1990 principalmente no Japão onde se encontra mais de trezentas mil toneladas de resíduos com TRs em sua composição [6]. Os elementos de terras raras são utilizados no metal hidreto principalmente para prender o oxigênio na bateria já que este era uma deficiência que suas antecessoras apresentavam [7].

As pilhas são compostas fisicamente por eletrodo positivo, eletrodo negativo, disco de PVC isolante, separador (tecido), ventilação, gaxeta, selo de proteção contra variações térmicas, copo metálico e terminal positivo, já na parte químicas baterias e pilhas são compostas por $\mathrm{Na}$ (Sódio), Al (Alumínio), Si (Silício), Cl (Cloro), K (Potássio), Mn (Manganês), Fe (Ferro), Co (Cobalto), Ni (Níquel), Cu (Cobre), Zn (zinco), La (Lantânio), Ce (Cério) [7].

De 1997 a 2012 o consumo de terras raras obteve um aumento de cerca de três vezes, já que foi a época em que muitos produtos começaram a ser produzidos com $\mathrm{NiMH}$ [8]. Encontrados em grandes quantidades na crosta terrestre, o nome foi dado por alguns elementos raros do grupo. As terras raras em si não são radioativas, mas quando extraídos de minerais, os próprios apresentam uma radiação involuntária, por estar em contato com principalmente com tório e urânio, assim tendo que passar por um processo não viável de purificação [9].

Com a tramitação na Câmara do Projeto de Lei 5807/2013 [10], que será a primeira lei especifica sobre terras raras, acabou dando o alavanque que faltava para estes minerais serem colocados oficialmente na economia e conhecidos pelo público como o chumbo e o cádmio.

As terras raras conhecidas desde 1787, por um mineralogista sueco que encontrou um silicato de cério e ítrio na Suécia, mas só em 1913, um físico inglês conseguiria completar o conjunto das terras raras [6]. Grupo de 17 elementos da tabela periódica, sendo 15 elementos do grupo IIIB lantanídeos o escândio e o ítrio que são metais de transição [11].

\section{MATERIAIS E MÉTODOS}

Foram adquiridas cerca de $5,7 \mathrm{~kg}$ de pilhas e baterias, obtidas de uma recicladora da USP. As pilhas e baterias seguiram para o processo de cominuição para dar sequencia aos processos de caracterização.

\footnotetext{
* Contribuição técnica ao 69ำ Congresso Anual da ABM - Internacional e ao 14ํㅡㄹ ENEMET - Encontro Nacional de Estudantes de Engenharia Metalúrgica, de Materiais e de Minas, 21 a 25 de julho de 2014, São Paulo, SP, Brasil.
} 


\subsection{Processamento Físico}

O processamento físico ocorreu inicialmente em britador tipo mandíbulas, seguido de moinho de facas, até grelha de $3 \mathrm{~mm}$.

Com o resíduo cominuído os materiais foram submetidos a separação magnética de tambor, nesta etapa espera-se que as terras raras se concentrem na fração magnética.

\subsection{Ensaios de Caracterização}

Os ensaios de caraterização envolvem etapas de digestão em água régia seguida de perda ao fogo a fim de classificar os tipos de materiais presentes nas pilhas e baterias. Com o licor da digestão em água régia foi possível identificar e quantificar os metais.

\subsubsection{Espectrometria de emissão optica com plasma acoplado indutivamente (ICP-OES)}

A análise do licor de digestão em água regia foi submetida a quantificação por ICPOES, os metais analisados Al; Cd; Ce; Co; Cu; Fe; La; Mn; Ni; Y; Zn.

\subsubsection{Digestão em água régia}

Este ensaio ocorreu durante $24 \mathrm{~h}$, razão entre massa/solução 1:20, sem aquecimento.

\subsubsection{Perda ao fogo}

Com o resíduo proveniente da digestão em água régia foi realizado o ensaio de perda ao fogo por $1 \mathrm{~h}$ a $800^{\circ} \mathrm{C}$.

\subsubsection{Fluorescência de Raio - $x$}

A análise do licor de digestão em água régia foi submetida a quantificação no Fluorescência de Raio - x, os metais analisados Al; Cd; Ce; Co; Cu; Fe; La; Mn; Ni; Y; $\mathrm{Zn}$.

\subsection{Ensaios Hidrometalúrgicos}

Os ensaios hidrometalúrgicos envolveram lixiviação com ácido sulfúrico $2 \mathrm{M}$, relação sólido/líquido 1:2.

Com o lícor foi realizado ensaio de ICP-OES.

\section{RESULTADOS E DISCUSSÃO}

\subsection{Processamento Físico}

Foram selecionadas cerca de 5,7kg de pilhas e baterias (conforme Figura 1), somente identificadas como sendo de níquel metal hidreto. Este lote foi cominuído em britador de mandíbula e moinho de facas.

\footnotetext{
* Contribuição técnica ao 69ำ Congresso Anual da ABM - Internacional e ao 14ํㅡㄹ ENEMET - Encontro Nacional de Estudantes de Engenharia Metalúrgica, de Materiais e de Minas, 21 a 25 de julho de 2014, São Paulo, SP, Brasil.
} 

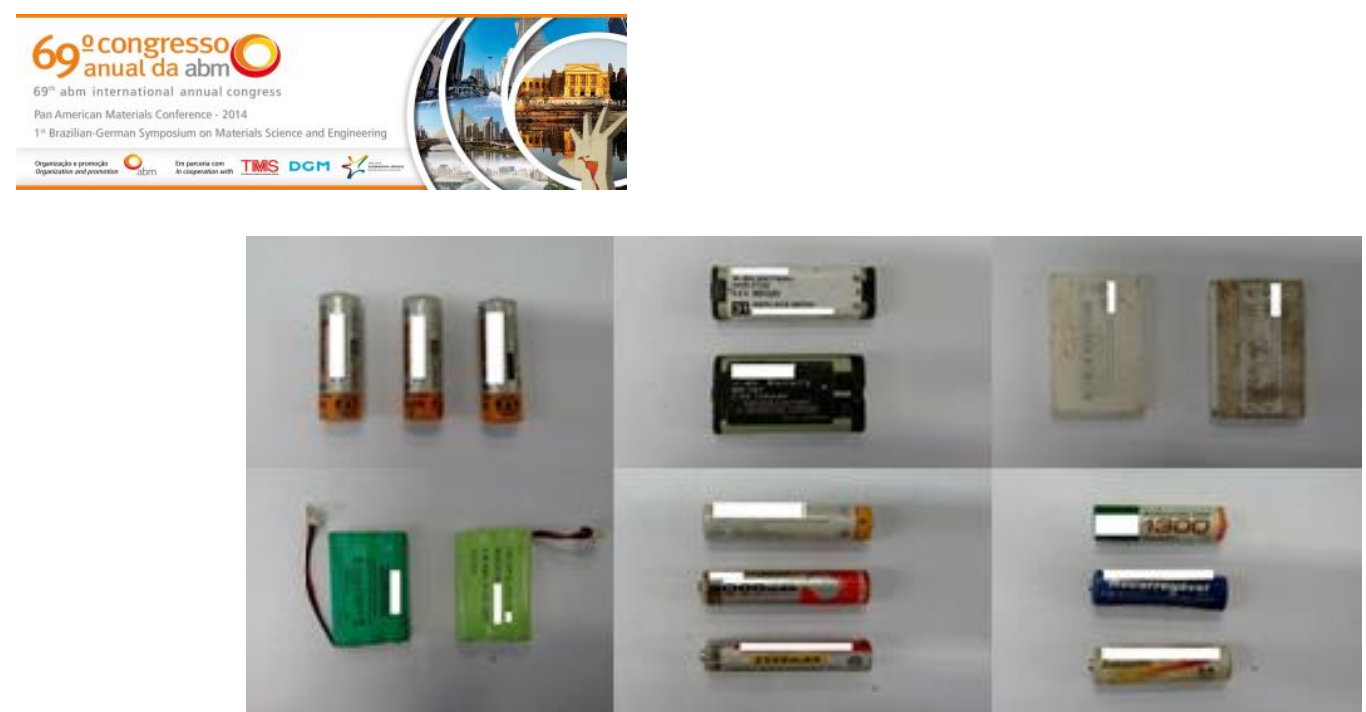

Figura 1 - Lote de pilhas e baterias utilizadas no processamento físico.

Totalizando as perdas de massa durante o processo de moagem com britador de mandíbulas e moinho de facas foi de $25 \%$.

Uma amostra quarteada de $5 \mathrm{~g}$ foi realizada a digestão em água régia e Fluorescência de Raio - x para quantificar os metais.

A porcentagem de perdas do processo de separação magnética foi de $20 \%$.

A quantidade de material magnético foi de $2,2 \mathrm{~kg}$ e material não magnético foi de $0,2 \mathrm{~kg}$. Os ensaios de digestão, Fluorescência de Raio - $x$ e ICP-OES foram realizados com a fração magnética a fim de quantificar os metais.

\subsection{Ensaios de Caracterização}

\subsubsection{Digestão em água régia}

A porcentagem de metais lixiviados em água regia foi de $100 \%$. A composição dos metais no licor de água régia foi analisada por fluorescência de raio-x.

\subsubsection{Perda ao fogo}

Com os valores de perda ao fogo foi possível caracterizar que $10 \%$ são materiais poliméricos e cerâmicos

\subsubsection{Fluorescência de Raio - $x$}

Os resultados obtidos pela Fluorescência de Raio - x estão descritos na tabela 1

Tabela 1 - Porcentagem em massa dos metais presentes no licor de lixiviação com água régia das pilhas e baterias, analisados por fluorescência de raio-x.

\begin{tabular}{|c|c|}
\hline Metais & \% em massa \\
\hline $\mathrm{Al}$ & 0,3 \\
\hline $\mathrm{Cd}$ & 9,7 \\
\hline $\mathrm{Ce}$ & 45,3 \\
\hline $\mathrm{Co}$ & 0 \\
\hline $\mathrm{Cu}$ & 4,0 \\
\hline $\mathrm{Fe}$ & 2,1 \\
\hline $\mathrm{La}$ & 1,2 \\
\hline $\mathrm{Mn}$ & 9,3 \\
\hline $\mathrm{Ni}$ & 1,4 \\
\hline $\mathrm{Y}$ & 25,9 \\
\hline $\mathrm{Zn}$ & 0,8 \\
\hline Total & 100 \\
\hline
\end{tabular}

\footnotetext{
* Contribuição técnica ao $69^{\circ}$ Congresso Anual da ABM - Internacional e ao 14ํㅡㄹ ENEMET - Encontro Nacional de Estudantes de Engenharia Metalúrgica, de Materiais e de Minas, 21 a 25 de julho de 2014, São Paulo, SP, Brasil.
} 


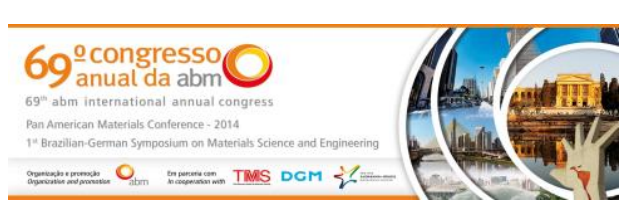

$\mathrm{Na}$ tabela 1 é possível observar que as pilhas e bateriais são compostas principalmente de cério e ítrio, que são dois elementos que compõem as terras raras.

\subsection{Ensaios Hidrometalúrgicos}

A amostra magnética foi lixiviada em ácido sulfúrico $2 \mathrm{M}$, durante $24 \mathrm{~h}$ a fim de extrair metais, incluindo as terras raras.

Os resultados obtidos pelo ICP-OES estão descritos na tabela 2

Tabela 2 - Porcentagem de extração dos metais presentes no licor de lixiviação com ácido sulfúrico das pilhas e baterias, analisados por ICP-OES.

\begin{tabular}{|c|c|}
\hline Metais & $\begin{array}{c}\text { \% de extração de Metais com ácido } \\
\text { sulfúrico (ICP-OES) }\end{array}$ \\
\hline $\mathrm{Al}$ & 23,7 \\
\hline $\mathrm{Cd}$ & 22,4 \\
\hline $\mathrm{Ce}$ & 100 \\
\hline $\mathrm{Co}$ & 100 \\
\hline $\mathrm{Cu}$ & 0,89 \\
\hline $\mathrm{Fe}$ & 100 \\
\hline $\mathrm{La}$ & 0 \\
\hline $\mathrm{Mn}$ & 15,0 \\
\hline $\mathrm{Ni}$ & 0 \\
\hline $\mathrm{Y}$ & 0 \\
\hline $\mathrm{Zn}$ & 28,4 \\
\hline
\end{tabular}

Com os resultados da Tabela 2 foi possível observar que o ácido sulfúrico tem maior seletividade na extração de Ce; Co e Fe.

O restante dos metais que não obtiveram lixiviação ou tiveram baixa porcentagem de extração deverão passar por mais uma rota de extração, seja em meio oxidante ou em ácido nítrico.

Para isolar os elementos de terras raras é necessária a purificação do licor lixiviado através de precipitação seletiva, extração por solvente ou cristalização.

\section{CONCLUSÃo}

Os resultados obtidos neste trabalho permite concluir que as pilhas e baterias de níquel metal hidreto tem como principais elementos de terras raras: cério e ítrio.

A lixiviação com ácido sulfúrico é seletiva para a extração de cério, cobalto e ferro.

A sequencia de lixiviação para extração de terras raras de pilhas e baterias de níquel metal hidreto deve contemplar: lixiviação em ácido sulfúrico, seguida de lixiviação em meio oxidante ou ácido sulfúrico. A purificação do licor lixiviado pode ser realizado através de precipitação seletiva, extração por solvente ou cristalização.

\section{Agradecimentos}

Capes, IGAmbiental, Departamento de Engenharia Metalúrgica e de Materiais da Escola Politécnica da USP, Senai de Tecnologia Ambiental - Mario Amato

\footnotetext{
* Contribuição técnica ao $69^{\circ}$ Congresso Anual da ABM - Internacional e ao 14ํㅡㄹ ENEMET - Encontro Nacional de Estudantes de Engenharia Metalúrgica, de Materiais e de Minas, 21 a 25 de julho de 2014, São Paulo, SP, Brasil.
} 


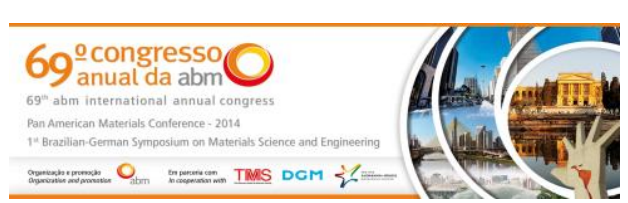

\section{REFERÊNCIAS}

1 Fishbein B. Insdustry Program to Collect Nickel-Cadmium (Ni-Cd) Batteries. (Online). Disponível na internet: http://www.epa.gov/epaoswer/hazwaste/recycle/battery.txt.

2 United States Environmental Protection Agency Product Stewardship- International Iniciatives for batteries (Online). Disponivel na Internet: http://www.epa.gov/epaoswer/nonhw/reduce/epr/products/bintern.html

3 Waste Watch Information Sheet: Battery Recycling (Online). Disponivel na Internet: http://www.wastewatch.org.uk/informtn/batteries.htm.

4 Conselho Nacional Do Meio Ambiente. 257/99: CONAMA. Distrito Federal, 1999.

5 Associação Brasileira De Normas Técnicas. NBR 16156:2013: Resíduos de Equipamentos Eletroeletrônicos - Requisitos para atividade de manufatura reversa. Campinas, [s.d].

6 Terras-Raras: Situação Atual E Perspectiva. Brasil: BNDES Setorial, v. 35, Fevereiro 2012. P. 369-420;

7 Espinosa DCR. Reciclagem de Baterias de Níquel-Cadmio. 2002. 195 f. Tese (Doutorado) Curso de Engenharia, Departamento de Metalurgia e Matérias, Escola Politécnica da Universidade de São Paulo, São Paulo, 2002. Cap. 1.

8 Consultoria Legislativa: Terras- Raras: Elementos Estratégicos para o Brasil. Câmara dos Deputados: Consultoria Legislativa, Fevereiro 2012.

9 Brasil. Congresso. Senado. Constituição (2013). Relatório, Subcomissão Temporária de Elaboração do Projeto de Lei do Marco Regulatório da Mineração e da Exploração de Terras Raras no Brasil- CCTSTTR: Relatório. Brasília, DF.

10 Coelho M. Brasil. Agência do Senado (Ed.). Subcomissão de Terras-Raras aprova relatório final. 2013. Disponível em:

<http://www12.senado.gov.br/noticias/materias/2013/09/10/subcomissao-de-terrasraras-aprova-relatorio-final>. Acesso em: 10 set. 2013.

11 Bertuol DA. Recuperação de Níquel, Cobalto e Terras Raras de Baterias de Níquel Metal Hidreto - NiMH. 2007. 160 f. Tese (Doutorado) - Curso de Engenharia, Departamento de Metalurgia e de Materiais, Universidade Federal do Rio Grande do Sul, Porto Alegre, 2008.

\footnotetext{
* Contribuição técnica ao 69ำ Congresso Anual da ABM - Internacional e ao 14ํㅡㄹ ENEMET - Encontro Nacional de Estudantes de Engenharia Metalúrgica, de Materiais e de Minas, 21 a 25 de julho de 2014, São Paulo, SP, Brasil.
} 